Case Report

\title{
Palateless Overdenture: A Case Report
}

\section{Malli Prakyath ${ }^{1}$, Bhat Vinaya ${ }^{2}$, Shetty Tripthi ${ }^{3}$}

${ }^{1}$ Senior Lecturer, Department of Prosthodontics, Yenepoya Dental college, Yenepoya University, Deralakatte, M angalore, ${ }^{2}$ Professor, Dept. of Prosthodontics, ${ }^{3}$ Post graduate student, Department of oral and maxillofacial surgery, A.B. Shetty M emorial Institute of Dental Sciences, Nitte University, Deralakatte, M angalore.

*Corresponding Author : Prakyath Malli, Senior Lecturer, Department of Prosthodontics, Yenepoya Dental College, Yenepoya University, Deralakatte, Mangalore 575018, M obile: +918095727027, E-mail : prakyath_m@ hotmail.com

Received

: 07.11.2016

Review Completed : 08.05.2017

Accepted

: 10.05 .2017

Keywords : Palateless over dentures, Telescopic over dentures, Gagging

\begin{tabular}{|c|}
\hline Access this article online \\
\hline Quick Response Code \\
\hline
\end{tabular}

\begin{abstract}
Palateless tooth supported overdenture is a treatment modality for patients to increase comfort as it aids in good retention, enhanced stability, better chewing efficiency and decreased alveolar bone resorption. This case report gives an insight into the step wise fabrication of a tooth supported palateless overdenture rather for better comfort, temperature and taste perception which is not possible as in case of a conventional complete denture.
\end{abstract}

\section{Introduction}

Many techniques have been described for successful prosthodontic management of completely and partially edentulous patients. Palateless complete denture provides a lot of advantages for edentulous patient. Following the uncovering of the palatal portion, it becomes easy for the patient to talk and also restores taste perception. It is also considered as an alternative for upper edentulous patients with extreme gag reflex and also in large inoperable palatal tori occurence. ${ }^{1}$

Using natural teeth to support a complete denture is not new in dentistry especially in cases where remaining natural teeth are not sufficient in number, position or stability to support either a fixed or a removable partial denture. Such a support can also be obtained when only the roots of the teeth are present to provide tensile stimulation to the residual alveolar ridge. This type of tensile stimulation through the periodontal attachments is conducive to bone repair and maintenance repair. ${ }^{2}$

\section{Case Report}

A 39 year old patient reported to the Department of Prosthodontics, with several missing maxillary teeth and missing 34, 35 and 36 (fig 1). Clinical and radiographic examination showed irreversible periodontal involvement of 22 and it was decided to be extracted. Considering the patient's previous periodontal status and limited number of abutments to support a fixed partial denture, it was decided to fabricate a telescopic palateless overdenture using the canines to support the primary copings and a cast circumferential clasp to support the molars.

Intentional root canal therapy of the abutments 13 and 23 were performed. The teeth were prepared with subgingival chamfer finish line to receive a primary coping (fig 2). Once the abutments were prepared, a suitable stock tray was selected and impression was made with putty (Aquasil soft putty/regular set, Dentsply,Germany) and light body (Aquasil LV, Dentsply, Germany) polyvinyl siloxane elastomeric impression material, by double step putty 
wash technique (fig 3). The impression was poured with die material (Kalrock, Kalabhai Karson Pvt.Itd., M umbai, India) to obtain cast on which pattern of copings was fabricated with crown wax (Crowax, Renfert, Germany).

The patterns of the copings were dome shaped. The patterns were then sprued (wires of sprue wax, Bego,Germany), invested (Bellasum, Bego, Germany), burnout and cast in base metal alloy (BEGO Wirocast $\mathrm{S}$, Bego, Germany). After retrieving casting from the investment, its fit was evaluated in the patient's mouth.
The primary copings were then picked up again with putty (Aquasil soft putty/regular set, Dentsply,Germany) and were finished to form the telescopic copings ( fig 4) over which the secondary copings would rest. It was then cemented on the abutments with glass ionomer cement (GCGold Label, GCCorporation, Tokyo, Japan).

A Cast partial denture framework with a circumferential clasp on the molars and mesh work minor connector over the copings was fabricated (fig 5). Occlusion rims were fabricated over trial denture base. Horizontal and vertical

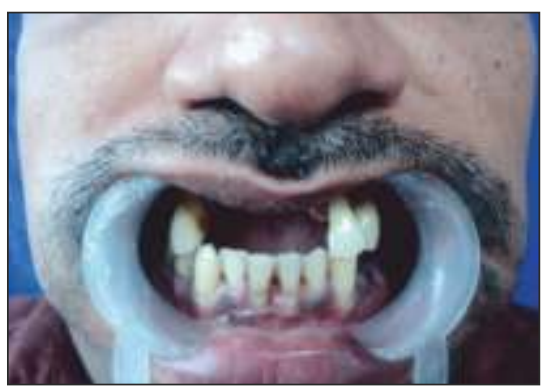

Fig 1 : Pre-op Vie

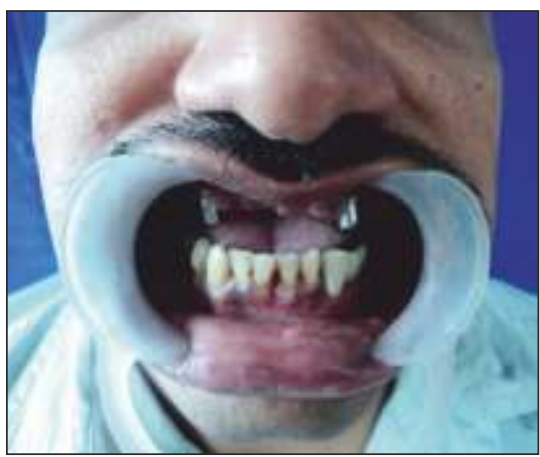

Fig 4 : Primary copings cemented on the abutments

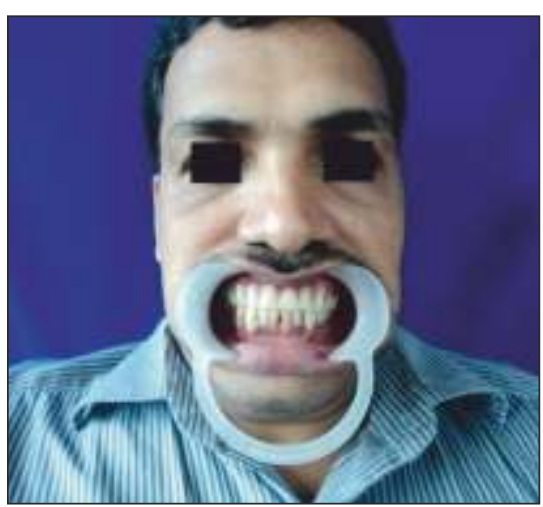

Fig 7 : Final prosthesis in the patient's mouth

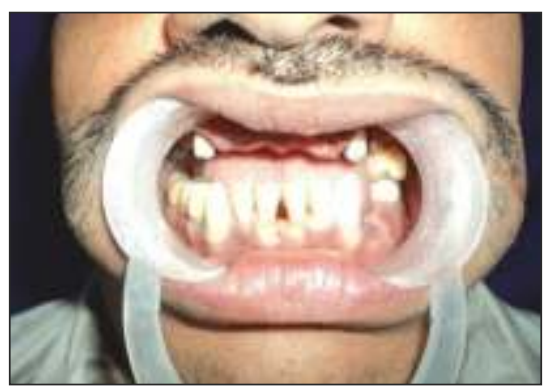

Fig 2 : Tooth prepared to receive primary copings

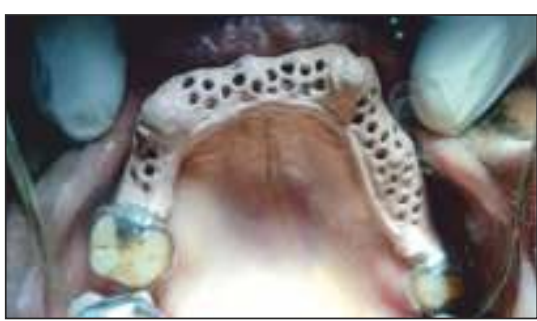

Fig 5: Metal framework fabricated over the primary copings

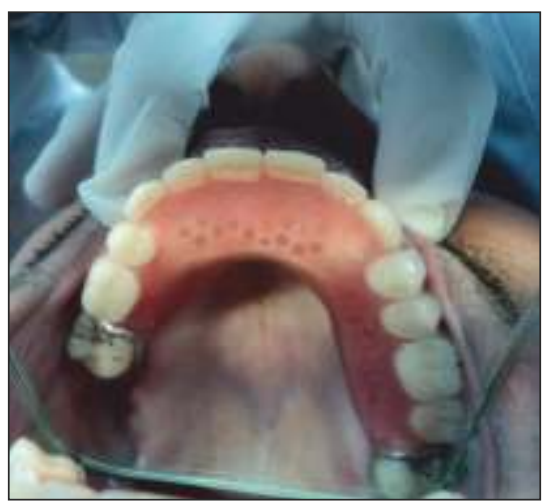

Fig 8 : Intra view of the palateless overdenture

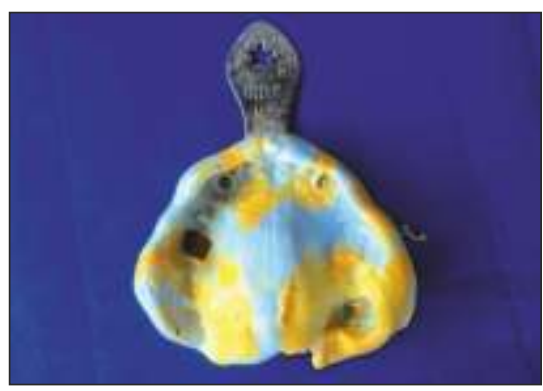

Fig 3 : Impression made with putty and light body of polyvinyl siloxane impression material.

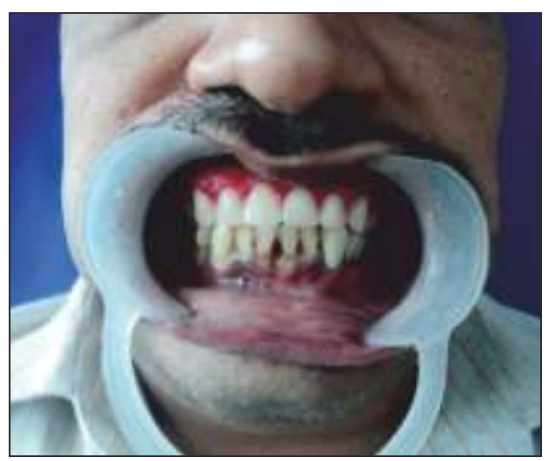

Fig 6 : Esthetic try in and verification of trial denture

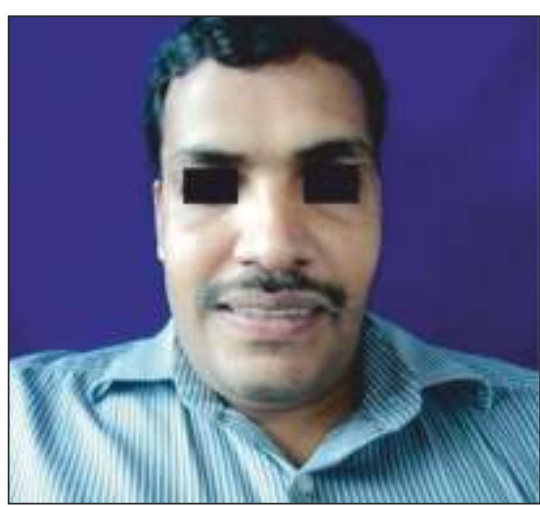

Fig 9 : post op view 
maxilla mandibular relations were recorded and it was transferred to a semi-adjustable articulator using a face bow record. Artificial teeth were arranged and evaluated intra orally for phonetics, esthetics. The jaw relations were verified (fig 6). After wax up, the denture was processed in heat cure acrylic resin (Lucitone, denture base material, Dentsply, Germany), finished, polished and inserted (fig 7). Figure 8 shows the intra oral view of palateless overdenture . The patient was scheduled for follow-up visits every 1 month. Figure 9 shows post operative view with final prosthesis in the mouth.

\section{Discussion}

Comfort has been the major issue ever prosthodontic replacement of missing teeth was thought of. During rehabilitation of maxilla, covering the palate completely leads to discomfort in speech and taste. Gagging is another reason where complete coverage maxillary prosthesis has its limitations. Wright ${ }^{3}$ in a classical study reported that $43.4 \%$ of the patients gagged only after having dentures and $83 \%$ associated the condition with stimulation and touching of the palate or back of the mouth. In addition, $24.5 \%$ felt that a reduction in palatal length greatly improved their ability to wear dentures due to decrease in touching and stimulation of the palate by the denture. Hence, palateless dentures have been advocated in the situation mentioned above.

In the past palateless denture technique has been previously described by Booth. ${ }^{4}$ When the denture is made

\section{References}

1. Song, E.H.; Kim, R.G.; Ahn, H.J.; Byun, S. and Choi, B.G. Palateless complete denture for restoring good tastes: A case report. J Korean Acad Prosthodont 1999.37(6): 819-824.

2. Heartwell CM, Rahn AO. Syllabus of complete dentures. Philadelphia: Lea and Febiger. 1986

3. Wright SM. Medical history, social habits, and individual experiences of patients who gag with dentures.J Prosthet Dent 1981; 45:474.

4. Booth L. Palateless Dentures. Oral health 1947; 32:118.

5. Langer A. Tooth supported telescopic restorations. J Prosthet Dent 1981;45: 515-520

6. Hou GL, Tsal CC, Weisgold AS. Periodontal and Prosthetic in severely advanced periodontitis by use of the crown and sleeve coping telescopic overdenture. A longitudinal case report. Aust Dent J 1997; 42:169-74

7. Langer $Y$, Langer $A$. Tooth supported telescopic prosthesis in compromised dentitions. A clinical report. J.Prosthet Dent 2000; 84: 129-32. palateless, it loses major amount of retention, stability and support required for the prosthesis success. Hence, other alternatives have to be sought after. Tooth supported removable partial dentures with telescopic crowns has been considered as an alternative to fixed restoration of the entire dental arch as they provide rigid splinting and stable occlusion and also offers better safety factor as they can be removed. They also decrease the dependence and strain on each single abutment. ${ }^{5}$ Positive successful results with telescopic over dentures in patients having reduced dentition and inflammation of the periodontium has been reported by Hou et al ${ }^{6}$ and also telescopic over denture helps in indirect splinting of the remaining abutment tooth. $^{\text {? }}$

Retention of palateless overdenture with telescopic retainers is completely dependent on the underlying abutment tooth. Hence it becomes compulsory for the dental clinician to periodically monitor their health and institute necessary steps to prolong its useful span.

\section{Conclusion}

Palateless overdentures have a clear advantage of offering comfort to the patient. However, other measures of obtaining the essential features like retention, stability and support should be carefully planned while treating the patient. The present article, reported one such situation where the patient was treated with palateless overdenture successfully. 